\title{
Empathy in children practising judo compared to their non-practicing peers
}

\author{
Grzegorz KOZDRAS* \\ University of Opole, Institute of Pedagogical Sciences (Poland)
}

8th IMACSSS International Conference Abstracts, Viseu (Portugal), October 10-12, 2019

Type: Oral communication

\begin{abstract}
Many authors dealing with martial arts and combat sports indicate that this form of activity contributes to limiting aggressive behavior towards other people. Contemporary psychological and pedagogical knowledge explains that empathy is one of the factors that determines a friendly and aggression-free attitude of people towards others. This study we compared the level of empathy between children practicing judo for a minimum of two years and their peers who did not practiced any martial art. Results showed higher levels of empathy in the group of judo practitioners. Judo trainers also agreed that judo participation may improve children's emotional development (emotional self-regulation and emotional self-awareness).
\end{abstract}

Keywords: Martial arts; combat sports; judo; empathy; sport pedagogy.

\section{Introduction}

Practising martial arts systems belonging budo family, including judo, may contribute to the reduction of aggressive behavior, as well as the reduction of the probabilities of the use of violence against other people (Cynarski, 2006; Hortiguela, Gutierrez-Garcia, \& Hernando-Garijo, 2017). This is related to the idea of martial arts participation aimed at the individual's physical, mental, and spiritual dimension development (Cynarski, 2012; Draeger, 2007; Takahashi, 2005; Tomas \& Saragoça, 2018). With the acquisition of the ability to fight, it becomes important for every "noble warrior" to develop empathy, which is one of the main factors conditioning the worthy use of this ability (Bagot, 1989; Kozdras, 2019; Ohsawa, 2011; Monteverde, 2009). Contemporary psychological and pedagogical knowledge largely explain the relationship between the level of empathy and aggressive behavior of people. This dependence shows that the higher the level of internalized empathy in people, the lower the ill-will and the aggression in them (Davis, 1999; Kaźmierczak, Plopa, Retowski, 2007). On this basis it can be assumed that if martial arts, including judo, really may reduce violence, then the level of empathy of these people will be higher than those who do not practice them.

\section{Objectives}

The main goal of this research was to compare the level of empathy between a group of children practicing judo for a minimum of two years and a group of children who did not practice any martial art. Secondarily, we also wanted to explore what elements accompanying the work of judo trainers may determine the development of empathy among young judokas.

\section{Methodology}

A quantitative research strategy was followed. A total of 134 children aged 8-12 participated in this study; 67 children who had been practicing judo for a minimum of two years, from five different groups, run by five different trainers, and 67 randomly selected children of the same age as the group of judokas, not practicing any martial art (control group). The Polish adaptation of Questionnaire to Asses Affective and Cognitive Empathy - QAACE (Ciechomski \& 
Surzykiewicz, 2015) was used. This questionnaire allows for determining the level of empathy by differentiating the cognitive (recognizing emotions) and the affective (responding to emotions) components. The questionnaire consists of 28 questions and a five-grade Likert scale for answers. A $t$-test for independent samples was used to compare judo and comparison group scores, and a Kruskal-Wallis test was used to compare the scores of the different judo groups.

\section{Results}

Table 1 shows the questionnaire results for both groups. The level of empathy of the judo group was higher than that of the comparison group $(p<.05)$. Significant differences were found for the affective factor but not for the cognitive factor.

Table 1. Results of $t$-test for independent samples

\begin{tabular}{|c|c|c|c|}
\hline Variable & Groups & $M$ & $S D$ \\
\hline Level of empathy & Judo group & 116,43 & $\begin{array}{l}10,06 \\
10,51\end{array}$ \\
\hline Cognitive factor of empathy & $\begin{array}{l}\text { Judo group } \\
\text { Control group }\end{array}$ & $\begin{array}{l}49.14 \\
47,41\end{array}$ & $\begin{array}{l}4,81 \\
5,43\end{array}$ \\
\hline Affective factor of empathy & $\begin{array}{l}\text { Judo group } \\
\text { Control group }\end{array}$ & $\begin{array}{l}67,28 \\
64,75\end{array}$ & $\begin{array}{l}7,47 \\
6,56\end{array}$ \\
\hline
\end{tabular}

There were also differences among judo groups which were led by different coaches (Table 2 ), so we can reject the null hypothesis about the equality of judo groups led by different coaches. This result also allowed me to select three judo coaches with whom I conducted an interview about their experiences on how to develop empathy in young judo athletes.

Table 2. Comparison of level of empathy obtained by judo groups led by different coaches.

\begin{tabular}{ccccc}
\hline Coach & $\boldsymbol{n}$ & Mean Rank & \multicolumn{2}{c}{ Kruskal-Wallis Test } \\
\hline A & 15 & 21,43 & Kruskal-Wallis $H$ & 21,67 \\
B & 11 & 35,09 & & \\
C & 11 & 38,27 & df & 4 \\
D & 11 & 21,23 & $p$ & 0,000 \\
E & 19 & 48,21 & $p$
\end{tabular}

\section{Discussion and Conclusion}

This study showed a higher level of empathy in children who practiced judo for a minimum of two years compared to children that did not practiced any martial art. As this was a crosssectional study, no causal relationship should be stablished. Further longitudinal studies could explore the reasons for young judokas may have higher levels of empathy, especially for the affective factor. In our opinion these children, who are often witnesses and co-participants of various emotional states with their peers when practicing judo, such as sadness after a failure, joy of victory, resignation as a result of a failure in performing an exercise, or fear of the opponent, could partially explain these results.

Considering the interviews with the three selected judo trainers, whose children achieved the highest scores in the empathy test, some common elements emerged. These elements, in the opinion of the surveyed trainers, determine the development of empathy in young judokas: open dialog, subjective treatment, righteousness, attending the smallest problems, ability to "read" children's emotions, collective search for solutions, willingness to pause training, emotional commitment, objective assessment of each person, asking questions about the emotions of others, and act every time when there is a problem in children's relationships.

In conclusion, empathy is a value that is worth being shaped and internalized among people because it creates an opportunity for a better understanding of each other. Empathy in judo 
contributes to the more effective implementation of the judo principle of training for the common good and benefit. Therefore, it seems necessary to present a humanistic-oriented methodology for judo teaching in children, thanks to which young people can be properly oriented towards socially desirable values and thus protect from the sometimes extrema sportification of martial arts and combat sports.

\section{References}

Bagot, B. N. (1989). Zen Judo: A way of life. London: Blandford.

Ciechomski, M., \& Surzykiewicz, J. (2015). Empathy can be developed - the family as the basic learning environment for compassion. Reflection and practical suggestions based on own research. In J. Bielski (Ed.), Multidimensional image of the modern family (pp. 325-338). Pultusk: Akademia Humanistyczna im. Aleksandra Gieysztora.

Cynarski, W. J. (2006). Reception and internalization of the ethos of Far-Eastern martial arts by practitioners. Rzeszów: Wydawnictwo Uniwersytetu Rzeszowskiego.

Cynarski, W. J. (2012). Anthropology of martial arts. Studies and sketches from sociology and philosophy of martial arts. Rzeszów: Wydawnictwo Uniwersytetu Rzeszowskiego.

Davis, M. (1999). Empathy: about compassion skills. Gdańsk: Gdańskie Wydawnictwo Psychologiczne.

Draeger, D. F. (2007). Contemporary Bujutsu and Budo. Bydgoszcz: Diamond Books.

Hortiguela, D., Gutierrez-Garcia, C., \& Hernando-Garijo, A. (2017). Combat versus team sports: the effects of gender in a climate of peer-motivation, and levels of fun and violence in physical education students. Ido Movement for Culture. Journal of Martial Arts Anthropology, 17(3), 11-20. doi: 10.14589/ido.17.3.2

Kaźmierczak, M., Plopa, M., \& Retowski, S. (2007). Empathy Sensitivity Scale. Przeglad psychologiczny, 1, 9-24.

Kozdras, G. (2019). Education in moral values of JUDO school students. Ido Movement for Culture. Journal of Martial Arts Anthropology, 19(1S), 50-54. doi: 10.14589/ido.19.1S.8

Monteverde, D. (2009). Judo. A Samurai Legacy. Los Angeles, CA: Lulu Publishing.

Ohsawa, G. (2011). The Book of Judo. California: George Ohsawa Macrobiotic Foundation Chico.

Takahashi, M. (2005). Mastering Judo. Champaign, IL: Human Kinetics.

Tomas J., \& Saragoça, J. (2018). Budo as philosophical background of Karate-Do: does the training method really matter? Ido Movement for Culture. Journal of Martial Arts Anthropology, 18(2), 38-42. doi: $10.14589 /$ ido.18.2.5 